\title{
Investigação geotécnica de um aterro sobre a várzea do rio Paraná Mirim no Município de Lauro de Freitas (BA) empregando as técnicas de eletrorresistividade e SPT
}

\author{
Marco A. Barsottelli Botelho (CPGG/IGEO/UFBA) e Juliana T. D. Gonçalves (PPEC/EP/UFBA)
}

Copyright 2018, SBGf - Sociedade Brasileira de Geofísica

Este texto foi preparado para a apresentação no VIII Simpósio Brasileiro de Geofísica, Salinópolis, 18 a 20 de setembro de 2018 . Seu conteúdo foi revisado pelo Comitê Salinópolis, 18 a 20 de setembro de 2018. Seu conteúdo foi revisado pelo Comité
Técnico do VIII SimBGt, mas não necessariamente representa a opinião da SBGf ou de seus associados. É proibida a reprodução total ou parcial deste material para propósitos comerciais sem prévia autorização da SBGf.

\section{Resumo}

A pesquisa tem o objetivo de avaliar a utilização de sondagens geofísicas não invasivas, particularmente a técnica de caminhamento elétrico (CE) do método geofísico de eletrorresistividade como ferramenta auxiliar para o diagnóstico geotécnico em investigações tradicionalmente feitas com sondagens de simples reconhecimento (SPT). Empregando-se oito (8) perfis CE e doze (12) ensaios de SPT, obteve-se uma boa correlação entre os dois tipos de ensaios, da ordem de $80 \%$, no que tange à definição de litologia e, consequentemente, no estabelecimento das propriedades geotécnicas. Os CE se apresentam como uma atraente alternativa para extrapolar os dados do SPT, permitindo uma visualização continua das características do subsolo estendidas ao longo de perfis, e ainda, reduzindo custos com sondagens diretas.

\section{Introdução}

Um projeto de engenharia necessita do conhecimento das características e propriedades geotécnicas do solo. A construção de uma ponte sobre o Rio Paraná-Mirim, no município de Lauro de Freitas (BA) necessitou de um aterro sobre a várzea do vale, por onde serpenteia o citado rio, para que a rodovia BA-093 acesse esta ponte. A estabilidade e/ou segurança da obra (aterro) depende da escolha do tipo de fundação a ser utilizada, portanto é imprescindível que sejam realizadas investigações do subsolo com os mais variados objetivos, como por exemplo, a determinação da profundidade e espessura da camada de solo, além de sua extensão lateral; o tipo de solo; a profundidade do topo rochoso e da alteração de rochas, capacidade de carga do terreno em diversas profundidades, entre outros. Essas informações foram obtidas com a investigação geotécnica utilizando o método direto denominado Standard Penetration Test (SPT), o qual é o método direto de investigação geotécnica mais popular no Brasil e em todo o mundo. Através do SPT é possível obter a estratigrafia do terreno ao longo do furo de sondagem e a resistência à penetração fornece uma classificação do solo de acordo com a compacidade (solos grossos compostos por areia ou silte arenoso) ou consistência (solos finos compostos por argila ou silte argiloso).

Os métodos geofísicos surgem como técnicas indiretas de investigação das estruturas em sub-superfície, sendo considerados como métodos não invasivos ou não destrutivos. $O$ método empregado foi 0 de eletrorresistividade, o qual constitui uma ferramenta para a análise geotécnica com baixo custo e rapidez na obtenção dos resultados. A técnica utilizada foi a do Caminhamento Elétrico (CE) com objetivo de gerar uma imagem da sub-superfície, em termos da distribuição de resistividades, a partir do que torna possível determinar a geometria das litologias. Por meio da técnica do CE, o qual foi aplicado ao longo de seis (6) linhas sobre a área de aterro, investiga-se as variações laterais do resistividade elétrica a diferentes profundidades. Os trabalhos de Xavier (2010), Popescu et al. (2016), Ling et al. (2016) e outros autores, revelam a utilidade dos métodos geofísicos para investigação geotécnica, que é a visualização contínua do subsolo, em duas ou três dimensões, trazendo uma visão mais ampla da área em estudo. Comparando os resultados do modelo geológico obtido com a geofísica aos resultados obtidos com sondagens SPT, que fornece somente informações 1-D, verifica-se que é praticamente impossível obter o mesmo modelo somente a partir dos SPTs pois, mesmo adensando e correlacionando os pontos de SPT, ainda que estes se situem muito próximos, não seria factível devido ao aumento dos custos e do tempo de execução. Finalmente, realizamos uma correlação entre a distribuição de resistividades e as informações litológicas e de resistência oriundas dos SPTs, de modo similar ao realizado no trabalho de Vogt (2012), onde utiliza-se a correlação entre sondagens SPT e o método da eletrorresistividade para avaliação das propriedades geotécnicas de uma encosta coluvionar.

\section{Metodologia/ Problema Investigado}

O aterro sobre a várzea do rio Paraná-Mirim foi investigado pelo método direto do Standard Penetration Teste (SPT) e pelo indireto do caminhamento elétrico (CA).

\section{O SPT}

O método direto utilizado nesta investigação geotécnica é o ensaio SPT, através do qual é possível obter a estratigrafia do terreno ao longo do furo de sondagem e a resistência à cravação do amostrador padrão por golpes de um martelo. Pode-se através de correlações, realizar a avaliação da densidade de solos granulares, consistência de solos coesivos, além de uma medida de resistência dinâmica associada à sondagem de reconhecimento (VOGT, 2012). Este método direto de investigação possui relativamente baixo custo, simplicidade de execução, tendo seu procedimento normalizado pela $A B N T$ através da norma ABNTNBR6484. A sondagem consiste essencialmente em dois tipos de operação: perfuração e amostragem. O procedimento de execução das sondagens SPT, seja a 
perfuração acima ou abaixo do nível d'água, ou a determinação do nível d'água, estão bem explanadas no trabalho de Pinto (2006) e em diversos outros livros e manuais de geotecnia. Uma breve descrição do procedimento SPT consiste no emprego de um amostrador denominado Terzaghi-Peck, o único que deve ser utilizado neste tipo de ensaio possui três partes: engate, corpo e sapata cortante. É constituído de tubos metálicos de parede grossa com corpo bipartido e ponta em formato de bisel, vide figura 01 .

O amostrador é conectado à haste e apoiado no fundo da perfuração. Em seguida é cravado pela ação de uma massa de ferro fundido (denominada de martelo) de $65 \mathrm{~kg}$. Para a cravação, o martelo é elevado a uma altura de $75 \mathrm{~cm}$ e deixado cair livremente. O alteamento do martelo é feito manualmente ou utilizando algum equipamento mecânico, através de uma corda flexível que passa por uma roldana existente na parte superior do tripé. A cravação do amostrador no solo é obtida por quedas sucessivas do martelo, até a penetração de 45 $\mathrm{cm}$. Vide a figura 02.

A informação referente ao estado do solo é considerada com base na resistência que ele oferece à penetração do amostrador. Durante a etapa de amostragem são anotados os números de golpes do martelo necessários para cravar cada trecho de $15 \mathrm{~cm}$ do amostrador. Os dados do primeiro trecho de $15 \mathrm{~cm}$ são desprezados e a resistência à penetração é definida como o número de golpes necessários para cravar $30 \mathrm{~cm}$ do amostrador. A resistência à penetração também é chamada como o número $\mathrm{N}$ do SPT, ou simplesmente, como SPT do solo. De posse da amostra colhida no amostrador e com o valor N do SPT é feita a identificação e classificação do solo, de acordo com a ABNT-NBR-7250.

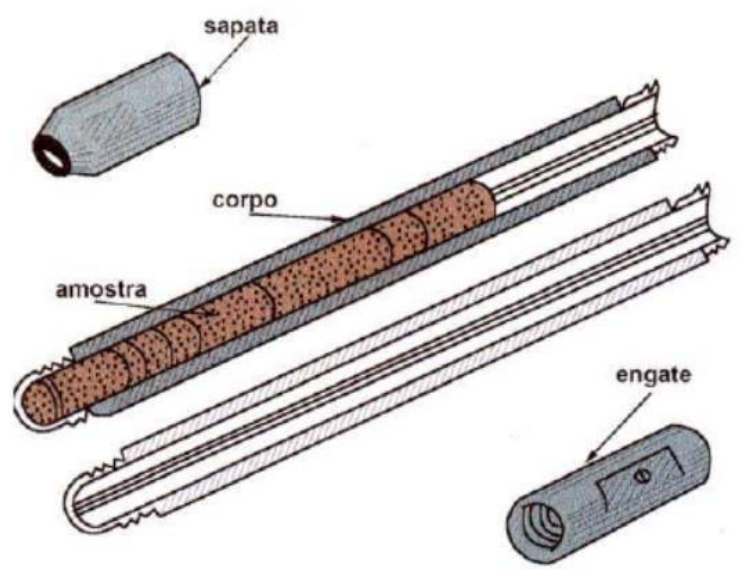

Figura 1 - Amostrador padrão de paredes grossas.

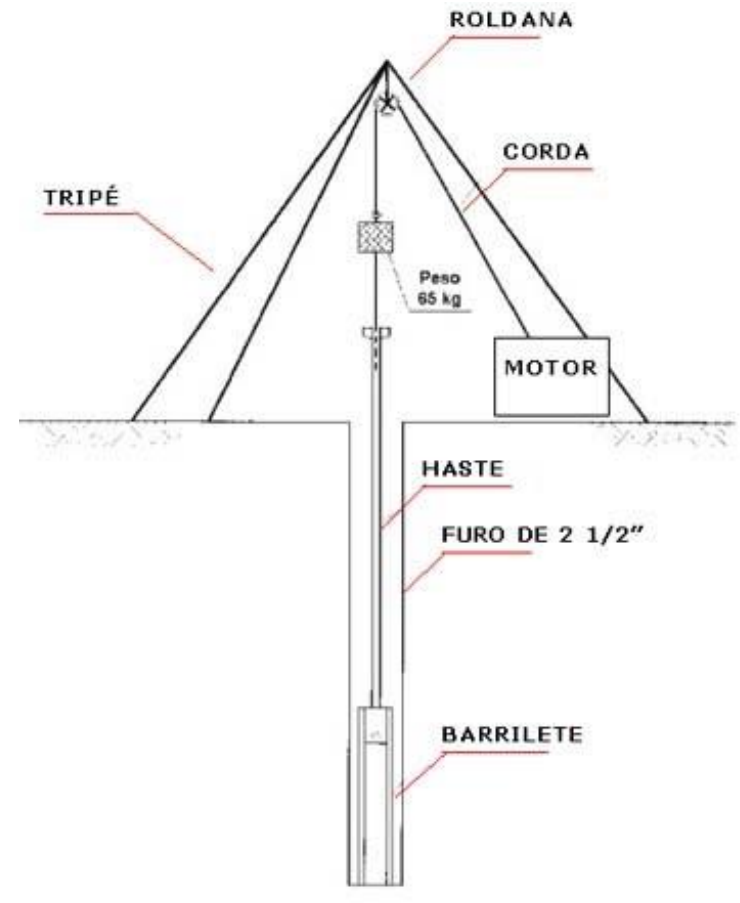

Figura 2 - Esquema de perfuração por percussão e amostragem (PINTO, 2006).

\section{O Caminhamento Elétrico}

O método geofísico usado é a eletrorresistividade e como pretendemos investigar não só a variação vertical da resistividade, mas também, as variações horizontais de resistividade, 0 procedimento adotado será o caminhamento elétrico (CE). Este caminhamento emprega arranjo de eletrodos do tipo dipolo-dipolo, com espaçamento entre os eletrodos de cinco (5) metros. As perfilagens CE longas $(210 \mathrm{~m})$ mapearam as variações laterais da resistividade e também as variações em profundidade até 22,0 metros. $\mathrm{O}$ arranjo dipolo-dipolo realizou medidas com arranjos de eletrodos $M N$ e $A B$ separados de até oito vezes (8.a) a separação padrão $(a=5 \mathrm{~m})$. Vide a figura 03.

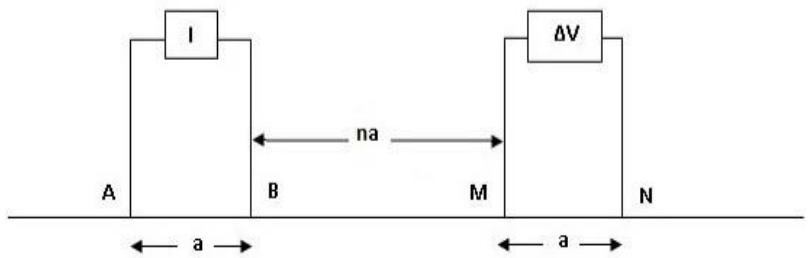

Figura 3 - Arranjo do tipo Dipolo-Dipolo utilizado nesta pesquisa com $a=5 \mathrm{~m}$ e $n$ variando de 1 a 8 .

Aquisição dos Dados

O croqui apresentado na figura 4 mostra a disposição dos oito (8) caminhamentos elétricos (CE) levantadas sobre o 
aterro. Os CE mais longos $(210 \mathrm{~m})$ mapearam as variações laterais da resistividade e também as variações em profundidade até 22,0 metros. O arranjo dipolo-dipolo realizou medidas com arranjos de eletrodos $M N$ e $A B$ separados de até oito vezes (8.a) a separação padrão $(\mathrm{a}=5 \mathrm{~m})$. A figura 05 mostra uma fotografia do aterro onde levantou-se os oito caminhamentos elétricos (CE) e ainda a disposição do cabo e eletrodos fincados no terreno no momento da aquisição do CE 3.

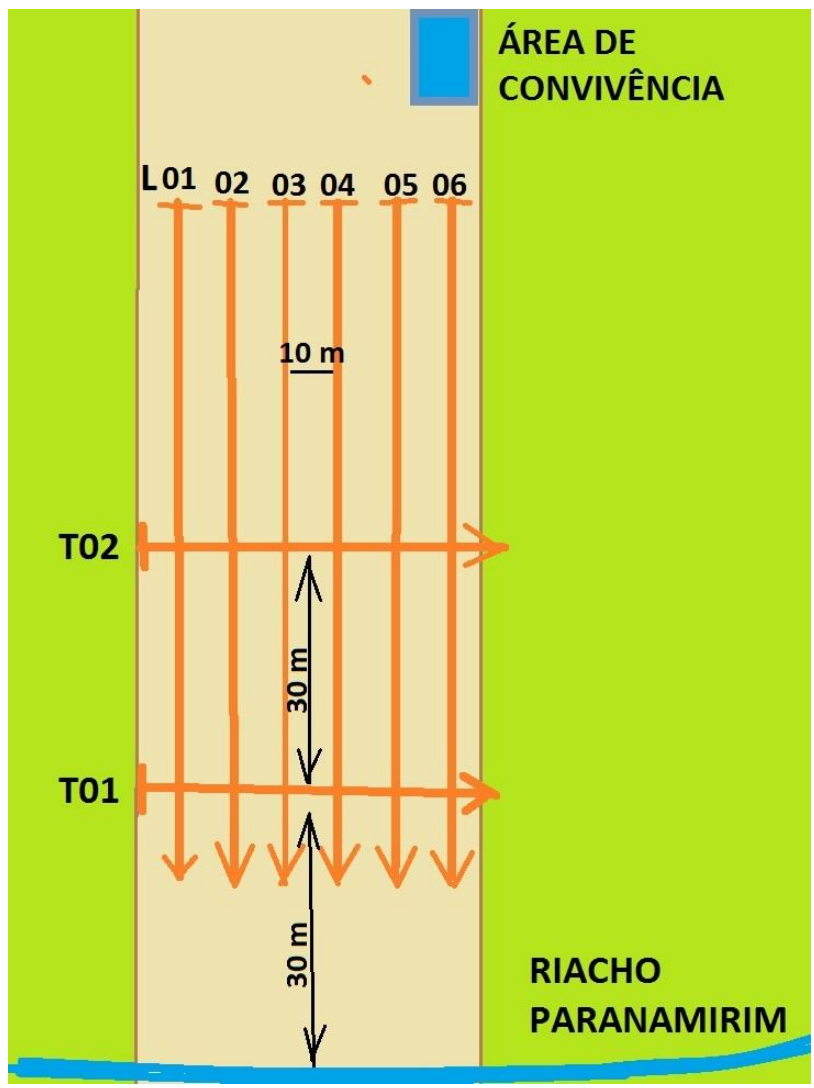

Figura 4 - Planta do posicionamento dos oito (8) caminhamentos elétricos (CE) levantados sobre o aterro na planície de alagamento do Rio Paraná Mirim.

\section{Resultados}

A seção de resistividade CE 05 revela uma camada superficial com resistividades entre 100 e 200 Ohm.m, com uma espessura média de $6,0 \mathrm{~m}$; abaixo desta camada, formada pelo aterro, há uma segunda camada que contém resistividades mais baixas, chegando a atingir valores de 2,0 a 10,0 Ohm.m, cuja espessura média também está em torno de $6,0 \mathrm{~m}$. Esta camada condutiva se assenta sobre blocos com maiores resistividades, variando de 200 a 2000 Ohm.m, tratandose de rochas alteradas sobre rochas cristalinas. Ao longo da quinta seção de eletrorresistividade foram realizados cinco (5) ensaios de SPT espaçados de aproximadamente quarenta (40) metros. Estes SPTs foram realizados na faixa $A$ da BR-093 (lado direito do aterro mostrado na figura 05) sobre a trajetória da quinta CA, sobre os pontos das estacas E-56, E-58. E-60, E-62 e E-64. Aos resultados do SPT serão acrescentados a variação vertical das resistividades, no ponto de localização de cada SPT, obtido a partir da seção de resistividade verdadeira correspondente ao CE 05. Estes resultados dos SPTs são integrados aos dados de resistividade dos CE, tal como nas figuras 06 e 07 , ilustrando os resultados nas estacas E-60 e E-64.

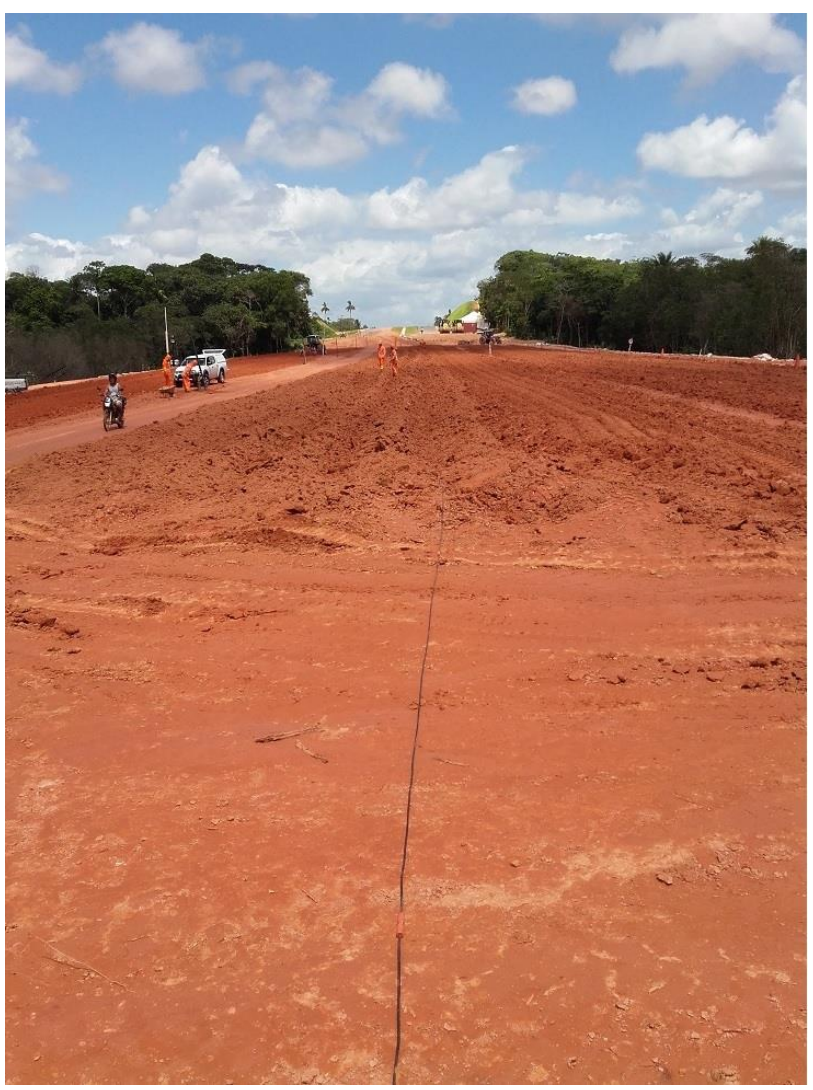

Figura 5 - Vista geral do aterro mostrando o cabo que conecta eletrodos no levantamento do CE 03.

Observa-se claramente nas estacas E-56 e E-60 que a presença de argila com matéria orgânica faz com que o SPT mostre que a penetração aconteça com poucos golpes, $\mathrm{N}_{\mathrm{f}}$ de 2 a 5 e, neste caso, a resistividade é em torno de 7 Ohm.m. Podemos ver nas estacas E-62 e E64 que ao atingir as profundidades e 9 a 10 metros 0 número de golpes $/ 30 \mathrm{~cm}$ passa para 30 , bem como a resistividade elétrica se situa agora entre 200 a 1000 Ohm.m, revelando um material mais resistente ao impacto, possivelmente rocha alterada. Este número de golpes atinge $50 / 30 \mathrm{~cm}$ e a resistividade passa de 1500 Ohm.m sugerindo uma rocha sã. Para uma melhor visualização do experimento e compreensão dos resultados apresenta-se as imagens correspondentes ao resultado do caminhamento elétrico (CA) de número 5 , levantado sobre a Faixa $A$ do trecho da via expressa BA093 que passa sobre o aterro. Na seção pode-se ver as posições das estacas onde foram levantados cinco (5) ensaios SPT na faixa $A$. 


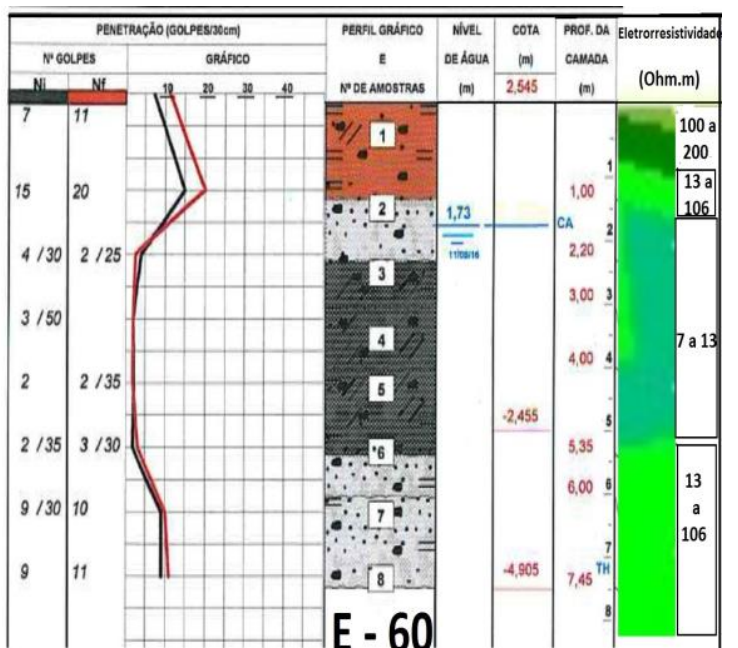

Figura 6 - Integração do ensaio SPT e a coluna da resistividade elétrica obtida sobre o quinto perfil longitudinal (LO5) na posição da estaca E-60.

\section{Discussão e Conclusões}

O levantamento geofísico empregando o caminhamento elétrico (CE) permitiu analisar a distribuição de resistividades ao longo do seu percurso, isto até uma profundidade média de vinte (20) metros. Integrando as seções de resistividade com as informações fornecidas pelos ensaios SPT, foi possível inferir a distribuição espacial $(x, z)$ das resistividades verdadeiras $e$ consequentemente das litologias. $O$ sucesso na geração destas seções $(x, z)$ de resistividade, a partir das quais pode-se fazer inferências sobre a distribuição de litologias, e de características geotécnicas, traz um novo papel para os CEs, ou seja, a extrapolação dos ensaios SPTs. Observa-se que neste local de pesquisa as rochas alteradas apresentam resistividades (500 a $15000 \Omega . m$ ) com $\mathrm{N}_{f}$ de 21 a 39; obviamente que a rocha sã é impenetrável e apresenta resistividades de 1500 a 3.000 Ohm.m. As argilas moles, muitas vezes orgânicas, apresentam baixas resistividades, de 2 a $10 \Omega$.m, e Nf de 2 a 5 ; praticamente se confundem com os siltes e areias finas com resistividades de 7 a $100 \Omega . m$ e Nf de 8 a 13 .

\section{Agradecimentos}

Os autores agradecem o incentivo e apoio provido pelo Prof. Luis Edmundo Prado de Campos, da Escola Politécnica da UFBA providos por meio de discussões técnicas sobre os resultados.

\section{Referências}

Gonçalves, J., 2016. Utilização do método de eletrorresistividade para mapear agentes causadores de instabilidade de taludes no Campus da UFBA - Trabalho

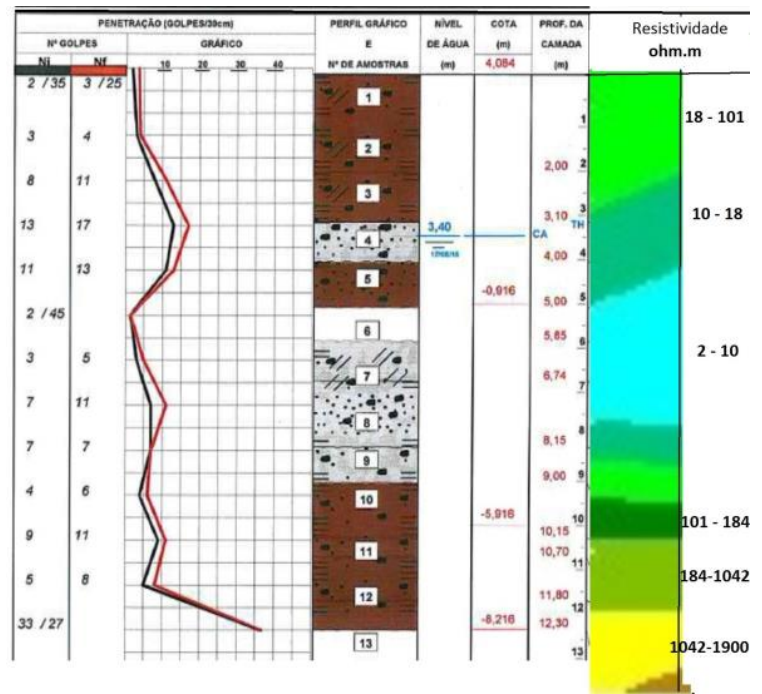

Figura 7 - Integração do ensaio SPT com a coluna de resistividade elétrica obtida sobre o perfil L05, na posição correspondente à estaca E-64.

de Conclusão de Curso, Departamento de Geofísica da Universidade Federal da Bahia, Brasil.

Ling, C., Xu, Q., Ran, J. \& Liv, H., 2016. Application of electrical resistivity tomography for investigating the internal structure of a translational landslide and characterizing its groundwater circulation (Kualiangzi landslide, Southwest China). Journal of Applied Geophysics, vol. 131: 154-162.

Pinto, C. S., 2006. Curso Básico de Mecânica dos Solos em 16 Aulas. Oficina de Textos. São Paulo, Brasil.

Popescu, M., Serban, R. D., Urdea, P. \& Onaca, A., 2016. Conventional Geophysical Surveys for landslides investigation: two case studies from Romania. Carpathian Journal of Earth and Environmental Sciences, vol. 11,n.1: 281-291.

Vogt, V., 2012. Avaliação Das Propriedades Geotécnicas De Uma Encosta Coluvionar No Oleoduto AraucáriaParanaguá (Olapa). Dissertação de Mestrado, Departamento de Engenharia Civil da Universidade Federal do Paraná, Brasil.

Zorzi, R. R. \& Rigoti, A., 2011. Aplicação de métodos geoelétricos para monitoramento da barragem de concreto da UHE Gov. José Richa. Boletim Paranaense de Geociências, vol.64-65: 48-58.

Xavier, F. F., 2010. Geofísica Elétrica Aplicada a Geotecnia para investigação de estabilidade de taludes. VII Simpósio de Práticas de Engenharia Geotécnica da Região Sul, ABMS, Foz do Iguaçu, PR, CD-ROM., 2010. 


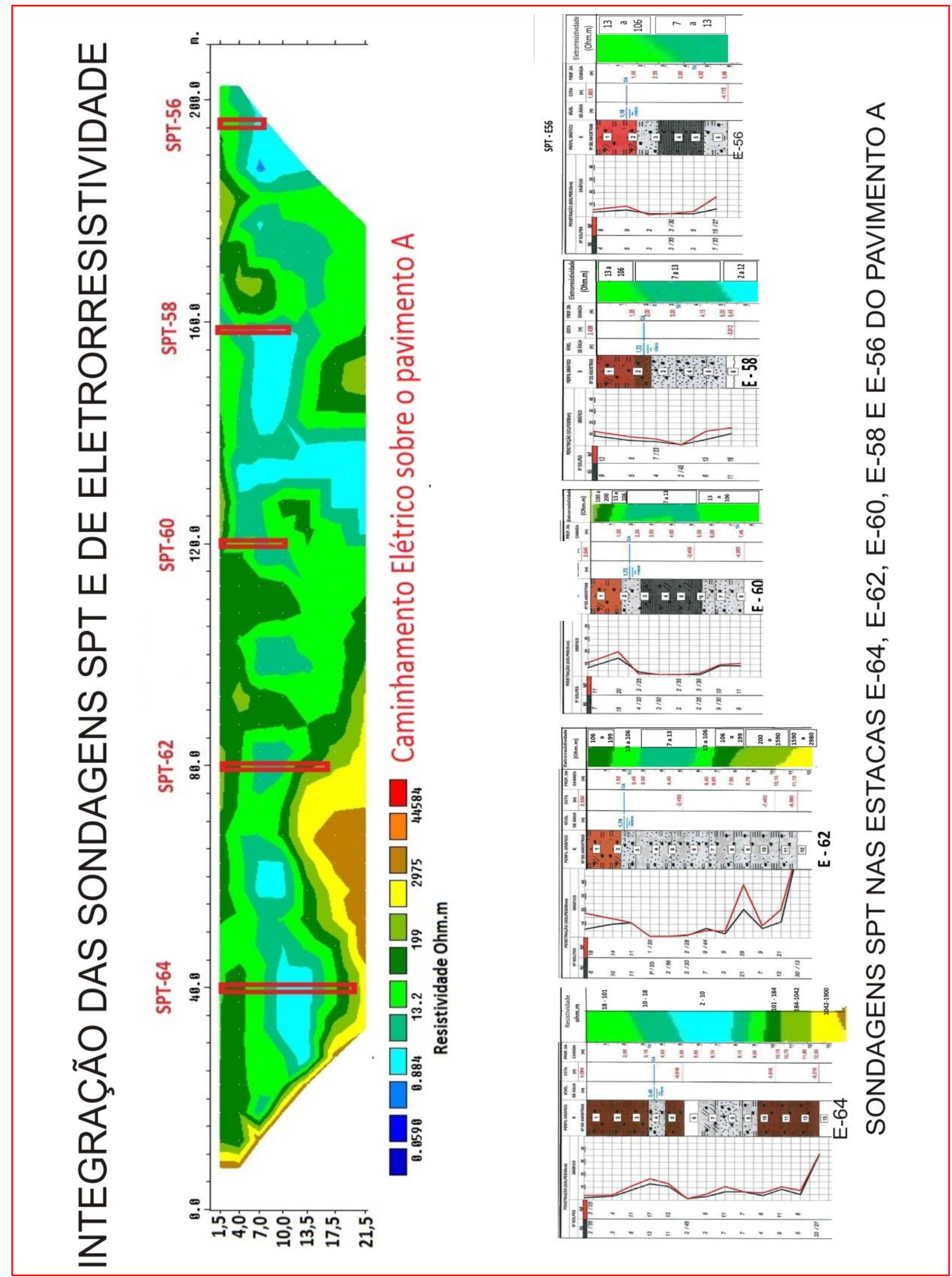

Figura 8 - Seção de eletrorresistividade obtida sobre o perfil L05 integrada com seis (6) ensaios SPTs. 